\title{
A contribuição do pensamento de Anísio Teixeira para a formação do cidadão democrático na sociedade brasileira
}

\author{
Mariana Balestrin¹, Breno Antônio Sponchiado², Edite Maria Sudbrack ${ }^{3}$
}

\begin{abstract}
Resumo
Este ensaio visa investigar os fundamentos da educação brasileira, com pretensão em educar para a democracia, através do pensamento de Anísio Teixeira. A revisão bibliográfica, ora apresentada, trata de alguns aspectos de sua vida e obra necessários para a compreensão deste ensaio. Discorre-se sobre a educação para a cidadania e democracia, conceitos balizadores do sistema educacional e por ele idealizados. Em meio a um cenário de desigualdades educacionais, discriminações, injustiças, pensamentos e ações dominantes, esse educador brasileiro lutou pela garantia de uma escola pública, universal e gratuita, entendida, por ele, como condição essencial para a democracia. Anísio também é apresentado como o idealizador da educação integral, em que prima pela indissociabilidade entre educação e vida, proporcionando as condições necessárias para o desenvolvimento de forma integrada. Nesse sentido, os escritos de Anísio Teixeira ainda se apresentam atuais e merecedores de serem visitados e estudados por formuladores de políticas para o sistema educacional brasileiro, gestores, professores e pesquisadores da educação escolar no país, uma vez que o projeto de democratização da escola pública brasileira ainda não se efetivou por completo, e, cada vez mais, tem-se a percepção que a educação é o caminho para a cidadania.
\end{abstract}

\section{Palavras-chave}

Anísio Teixeira. Educação. Cidadania. Democracia.

1. Mestre em Educação pela Universidade Regional Integrada do Alto Uruguai e das Missões, Rio Grande do Sul, Brasil; professora substituta da Universidade Federal de Santa Maria, Campus Palmeira das Missões, Rio Grande do Sul, Brasil. E-mail: maridalmolin@hotmail.com.

2. Doutor em História pela Pontifícia Universidade Católica do Rio Grande do Sul, Brasil; professor titular da Universidade Regional Integrada do Alto Uruguai e das Missões, Campus de Frederico Westphalem, Rio Grande do Sul, Brasil. E-mail: sponchiado@uri.edu.br.

3. Doutora em Educação pela Universidade Federal do Rio Grande do Sul, Brasil; professora da Universidade Regional Integrada do Alto Uruguai e das Missões, Rio Grande do Sul, Brasil. E-mail: sudbrack@uri.edu.br. 


\title{
The contribution of Anísio Teixeira's thought to the formation of the democratic citizen in Brazilian society
}

\author{
Mariana Balestrin*, Breno Antônio Sponchiado**, Edite Maria Sudbrack ${ }^{* * *}$
}

\begin{abstract}
This essay aims to investigate the fundamentals of Brazilian education with a pretension to educate for democracy, through the thought of Anísio Spínola Teixeira. The bibliographical review deals with some life and work aspects of Anísio Teixeira, which are necessary for the understanding of his studies. Education for citizenship and democracy, concepts that guide the educational system idealized by the educator are discussed. In an educational inequalities discriminations, injustices, thoughts and dominant actions scenario, Anísio Spínola Teixeira fought for the guarantee of a public, universal and free school, understood by him as an essential condition for democracy. Anísio is also presented as the idealizer of the integral education, which stresses the inseparability between education and life, providing the necessary conditions for development in an integrated way. In this sense, the writings of Anísio are still currently worth of being visited and studied by the policy makers for the Brazilian educational system, by the managers, teachers and researchers of the school education in the country, once the democratization project of the Brazilian public school has not been yet fully materialized, and more and more, there is the perception that the education is the way to citizenship.
\end{abstract}

\section{Keywords}

Anísio Teixeira. Education. Citizenship. Democracy.

\footnotetext{
* Msc in Education, Integrated Regional University of Alto Uruguai e Missões, State of Rio Grande do Sul, Brazil; substitute professor at Universidade Federal de Santa Maria, Campus Palmeira das Missões, State of Rio Grande do Sul, Brazil. E-mail: mari_dalmolin@hotmail.com.

** PhD in History, Pontifical Catholic University of Rio Grande do Sul, State of Rio Grande do Sul, Brazil; professor at Integrated Regional University of Alto Uruguai e Missões, Campus de Frederico Westphalem, State of Rio Grande do Sul, Brazil. E-mail: sponchiado@uri.edu.br.

*** PhD in Education, Federal University of Rio Grande do Sul, State of Rio Grande do Sul, Brazil; professor at Integrated Regional University of Alto Uruguai e Missões, Campus de Frederico Westphalen, State of Rio Grande do Sul, Brazil. E-mail: sudbrack@uri.edu.br.
} 


\section{Introdução}

A trajetória de Anísio Teixeira traz a marca e o compromisso de uma escola democrática, na defesa de uma educação pública, universal e gratuita. A escola deve formar cidadãos. Assim, para alcançar tal objetivo, é preciso uma educação para a democracia, capaz de formar sujeitos ativos e participativos e que saibam viver em sociedade.

Inspirado pelo filósofo e pedagogo norteamericano John Dewey, Anísio Teixeira trouxe várias contribuições à educação do Brasil. $\mathrm{O}$ intelectual Anísio soube propor uma forma própria e necessária para resolver as questões educacionais brasileiras. Foi assim na luta empreendida em defesa da escola pública brasileira como via para a consolidação da democracia, bem como no projeto de educação integral e em tempo integral, defendido como pressuposto necessário para a garantia da igualdade de oportunidades educacionais.

Estudioso das questões educacionais, Anísio foi, também, homem de ação que buscou, na medida do possível, transformar o sistema educacional do país, contribuindo para a formação do pensamento pedagógico brasileiro.

Inicialmente, a revisão bibliográfica faz referência a aspectos da vida e obra de Anísio Teixeira, considerados necessários para a compreensão deste ensaio. Faz-se importante resgatar sua trajetória intelectual e profissional e sua notável participação em reformas da instrução pública e como signatário no Manifesto dos Pioneiros da Escola Nova para entender seu envolvimento com o sistema educacional brasileiro. Na sequência, discorre-se, sobre a educação para a cidadania e para a democracia, de acordo com os princípios defendidos por Anísio Teixeira, a fim de entender como, para ele, a educação formará um cidadão democrático.

Tendo como princípio o discurso educacional e as práticas sugeridas por Anísio Teixeira, nos tópicos que seguem, privilegiou- se o esclarecimento da educação para a democracia e cidadania, proposta por ele. Essas noções ainda se encontram em construção, porém, Anísio nos fornece grandes contribuições para o melhor entendimento da educação como o caminho para o exercício da cidadania.

\section{Vida e obra de Anísio Teixeira}

Anísio Spínola Teixeira nasceu no dia 12 de julho de 1900, na cidade de Caetité, Bahia. Filho do médico e fazendeiro Deocleciano Pires Teixeira e Anna Souza Spínola Teixeira (FARIAS; AMARAL; SOARES, 2001).

Iniciou seus estudos na escola primária de Dona Maria Teodolina das Neves Lobão e, em seguida, estudou na escola da professora Prescila Spínola, sua tia. Ainda em Caetité, estudou no Instituto São Luís e, posteriormente, na companhia de dois de seus irmãos, partiu para Salvador, onde estudou no colégio jesuíta Antônio Vieira (SAVIANI, 2007). Nesse colégio, Anísio teve contato com muitos professores de grande importância, que detinham a vocação sacerdotal e acadêmica.

Surgiu, então, o desejo de ingressar no Seminário da Companhia de Jesus e ordenarse padre, contudo, não obteve o consentimento dos pais. Assim, transferiu-se, mais tarde, para o Rio de Janeiro, onde se bacharelou em Direito, na antiga Faculdade de Ciências Jurídicas e Sociais da Universidade do Rio de Janeiro, em 1922, ano do Centenário da Independência (SAVIANI, 2007).

No ano seguinte, retornou ao seu Estado, no intuito de obter de seu pai a permissão para ingressar na Ordem dos Jesuítas, disposto a viver para a sua fé e entrar para o seminário, mas a oposição da família novamente o fez desistir. (FARIAS; AMARAL; SOARES, 2001). Sua família possuía trajetória assegurada na política baiana, 
uma das alternativas profissionais bastante presentes na vida de Anísio (SAVIANI, 2007).

O pai de Anísio via nele um magistrado nato, seu sucessor natural, futuro patriarca familiar. Padre Cabral via nele uma vocação para o sacerdócio e, pelos seus talentos, alguém destinado a ocupar postos importantes na hierarquia eclesiástica. (NUNES, 2010, p. 14).

Os interesses externos se confrontavam com os internos e, em meio a esses conflitos, Anísio Teixeira iniciou sua vida pública em 1924, ocupando o cargo de Inspetor Geral de Ensino na Bahia. No cargo, teve a oportunidade de realizar amplas reformas na instrução pública daquele estado.

Por força do cargo assumido, entrou, pela primeira vez, em contato com uma literatura pedagógica e um sistema público de educação que não conhecia. Em oposição à cultura, à organização, à competência docente dos colégios nos quais estudara, deparou-se - na capital do seu estado natal - com a pobreza de recursos materiais e humanos. Observou também a dispersão e a desarticulação dos serviços educativos, o despreparo do professor, a imoralidade, a corrupção e a acomodação dos poderes públicos, alimentando a ineficiência da máquina estatal. (NUNES, 2010, p. 16).

No período compreendido entre 1924 e 1929, Anísio teve a oportunidade de realizar viagens para a Europa e Estados Unidos. Em uma dessas viagens conheceu o filósofo americano John Dewey, que marcou decisivamente sua trajetória intelectual. Em 1930, Anísio Teixeira publicou a tradução de dois ensaios de John Dewey, que receberam o nome de "Vida e educação" (NUNES, 2000). John Dewey era um pensador que denunciava, nos Estados Unidos, que a ameaça da democracia não estava fora do país, mas dentro dele, nas atitudes pessoais e nas instituições. Segundo Nunes (2010, p. 19), o pragmatismo deweyano forneceua Anísio "um guia teórico que combateu a improvisação e o autodidatismo, permitiu-Iheoperacionalizaruma política e criar a pesquisa educacional no país".

Em 1931, Anísio Teixeira assume por influência do prefeito Pedro Ernesto Batista, a diretoria da Instrução Pública do Distrito Federal. Ali, teve a oportunidade de conduzir importante reforma da instrução pública, que atingiu a escola primária, a escola secundária e o ensino de adultos, com a formação da Universidade do Distrito Federal. Porém, demitiu-se em 1935, diante das pressões políticas que inviabilizaram sua permanência no cargo (NUNES, 2000).

Por meio da educação, buscou consolidar as conquistas democráticas da Revolução de 1930 e se deparou com a necessidade de construir um partido revolucionário, que passou a ser chamado Partido Autonomista do Distrito Federal, constituindo-se como a base do ideário e gestão de Pedro Ernesto. Porém, a pessoa de Pedro Ernesto acabou por prevalecer sobre o programa, resultando na saída de Anísio Teixeira da vida pública e a interrupção dos projetos educacionais (SAVIANI, 2007).

Anísio demitiu-se em 1935, em consequência da conjuntura política que impossibilitava sua permanência no cargo, haja vista que o pensamento autoritário ganhava força no Estado e na sociedade. Em 1936, publicou o livro Educação para a democracia: introdução à administração educacional. Além disso, realizou traduções de obras de autores como Wanda Pompeu Geribello, Alfred Adler e John Dewey para várias editoras, porém suas traduções tiveram de ser interrompidas, pois sua atividade intelectual também atrapalhava a política ditatorial do Estado Novo. Anísio desenvolveu, então, suas habilidades para o comércio e indústria, com a exportação de minérios na Bahia.

Após o término da Segunda Guerra Mundial foi criada a Organização das Nações Unidas para a Educação, a Ciência e a Cultura (Unesco) e, em 1946, Anísio recebeu o convite de Julien Sorell Huxley, primeiro-secretário 
executivo da Organização, para assumir o cargo de Conselheiro de Ensino Superior. Contudo, em 1947, deixou a Unesco e retornou para a vida privada. Neste mesmo ano, com a abertura democrática do país, Anísio foi convidado por Otávio Mangabeira, governador da Bahia, a assumir o cargo de Secretário da Educação, onde permaneceu até o ano de 1951 (SAVIANI, 2007).

Uma das mais importantes iniciativas de Anísio Teixeira na condução dessa pasta foi a construção do Centro Popular de Educação Carneiro Ribeiro, popularmente denominado de Escola-Parque, no bairro da Liberdade. A Escola-Parque, inaugurada em 1950, procurava fornecer à criança uma educação integral, cuidando de sua alimentação, higiene, socialização e preparação para o trabalho e a cidadania. Esta obra projetou-o internacionalmente. (NUNES, 2000, p. 1112).

Ainda em 1951, a convite do Ministro da Educação, o jornalista e advogado Ernesto Simões da Silva Filho, retornou à ação no governo Federal e assumiu a Secretaria Geral da Campanha - posterior Comissão de Aperfeiçoamento do Pessoal do Ensino Superior (Capes), fundada em junho desse mesmo ano e por ele transformada no órgão que impulsionou os cursos de pós-graduação. No ano seguinte, sucedendo Murilo Braga de Carvalho, assumiu, também, o cargo de diretor do Instituto Nacional de Estudos Pedagógicos (Inep) (FARIAS; AMARAL; SOARES, 2001). Nesse período, proferiu diversas conferências e participou da discussão da Lei de Diretrizes e Bases da Educação Nacional (1961). E, então,emumperíodoemqueaeducação era tratada como um privilégio das elites, Anísio escreveu o livro Educação não é privilégio (1957), em que defendia que a educação é um direito de todos e não um privilégio de poucos. Escreveu também a obra $A$ educação e a crise brasileira (1956). Em virtude da ditadura militar iniciada em 1964, foi afastado da vida pública.
Atendendo a convites das Universidades de Colúmbia (1964), Nova Iorque (1965) e Califórnia, foi para os Estados Unidos lecionar como professor visitante. Quando retornou ao Brasil, em 1966, tornou-se consultor de assuntos educacionais da Fundação Getúlio Vargas. No período entre 1966 e 1971, escreveu seus últimos dois trabalhos: Educação e o mundo moderno (1969) e Educação no Brasil (1969).

No dia 11 de março de 1971, em uma quinta-feira, por volta de 11h30min, Anísio deixou a sede da Fundação Getúlio Vargas, no Rio de Janeiro, rumo ao apartamento de Aurélio Buarque de Holanda, mas não chegou. Foi encontrado morto no poço do elevador do edifício onde residia o escritor. (FARIAS; AMARAL; SOARES, 2001).

\section{Educação para a cidadania}

Para Anísio Teixeira, um contexto histórico vivido por qualquer povo necessita de quatro instituições indispensáveis: "a família, o Estado, a Igreja e a escola" (TEIXEIRA, 1997, p. 98). Entre elas, a escola é a maior responsável pela formação de cidadãos e socialização do ser humano. Para o autor, a educação escolar não se limitava à alfabetização, tinha a missão maior de elevar o nível cultural dos indivíduos frequentadores da escola. Anísio atribuía especial importância e inferia à escola tamanha responsabilidade por afirmar que a família apresentava-se enfraquecida, devido à reconstrução social moderna. Nesse contexto, havia necessidade da escola ampliarseus deveres:

até participar de todos os deveres do lar, assumindo a responsabilidade de dar às crianças todas as condições que lhe asseguram - ou lhe deviam assegurar - na família, a continuidade e a integridade de uma ação formadora completa. Educação e não instrução apenas. Condições de vida e não condições de ensino somente. Mas nem por isso a escola substitui integralmente o lar. Esse 
continuará e, para continuar, deve também ser refundido em suas bases intelectuais e sociais, como já o foi nas suas bases econômicas. (TEIXEIRA, 1997, p. 65).

Em diversos momentos, Anísio Teixeira chegou a considerar perniciosa a alfabetização por si mesma, afirmando que "desacompanhado de educação, o miraculoso alfabeto, em verdade, só produz males" (TEIXEIRA, 1997, p. 83). Para ele, o sistema educacional precisava ir muito além; deveria conseguir munir seus alunos de meios que os tornassem aptos para "participar, plenamente, de acordo com as suas capacidades naturais, na vida social e econômica da civilização moderna" (TEIXEIRA, 1997, p. 86). Quer dizer, a escola tem um papel socializador, de preparar indivíduos para a democracia.

Ao se falar em indivíduos deve-se ter em mente que os homens se associam de todos os modos e entre diferentes grupos. Portanto, o modo de vida associada faz com que grupos (compostos por vários indivíduos, cada um com sua individualidade) que nada têm em comum, figurem em uma mesma sociedade. Nessa ótica, existem subdivisões políticas, industriais, científicas, religiosas (TEIXEIRA, 1997, p. 86). Os indivíduos que fazem parte dessa sociedade diversificada também são conhecidos como cidadãos. Cada indivíduo tem suas peculiaridades, assim, as pessoas conseguem realização utilizando seus talentos para contribuir com o bem-estar da comunidade. Desta forma, a educação surge com a função de ajudar a criança a desenvolver um "caráter", ou seja, um conjunto de hábitos e virtudes que permitem ao sujeito realizar-se plenamente (WESTBROOK; TEIXEIRA, 2010). Logo, formar o cidadão tornou-se meta da educação.

Para situar a noção de cidadania e o papel da escola em Anísio Teixeira, é preciso, primeiramente, compreender a sociedade por ele almejada, pois acreditava ser a escola "uma réplica da sociedade a que ela serve" (TEIXEIRA, 1930a, p. 15). Assim, para compreender o pensamento de Anísio Teixeira é importante situar o movimento educacional renovador brasileiro, cujas bases encontram-se no escolanovismo, surgido em fins do século XIX, na Europa e nos Estados Unidos. Este movimento opunha-se às práticas pedagógicas tidas como tradicionais, visando uma educação que pudesse integrar o indivíduo à sociedade e, ao mesmo tempo, ampliar o acesso de todos à escola.

Para uma nova concepção de educação para o milênio que se inicia, Cordeiro (2001), citando Anísio Teixeira, destaca sua estruturação a partir de quatro pilares: "aprender a conhecer", "aprender a fazer", "aprender a viver juntos" e "aprender a ser". De acordo com o pensamento de Anísio, quando essas concepções se relacionam, elas permitem a construção do caráter do sujeito.

Em uma sociedade democrática não cabe um homem voltado exclusivamente para seus próprios interesses, portador de um saber estático. O homem é um ser social, um ser que desenvolverá suas especificidades individuais, mas ciente de sua importância e repercussão no âmbito social. Porém, essa consciência não é inata, ela é construída.

Nessa perspectiva, a escola se propõe a mostrar a realidade em que alunos estão inseridos e a sociedade em que vivem, permitindo a sua compreensão. A escola pode, dessa maneira, proporcionar uma educação centrada na prática dos mais diversos contextos da vida cotidiana, pois educar é muito mais do que ensinar o conhecimento científico, é educar para a cidadania. Embora se possa questionar se há a possibilidade de educar para a cidadania, é necessário, em caso afirmativo, explicar o que se entende por cidadania.

Anísio define que a cidadania não nasce espontaneamente em uma sociedade, sendo construída pela tomada de consciência da coletividade. Cidadania implica em direitos e deveres para com o grupo social. Só será 
cidadão o indivíduo que compreender-se como agente participativo e responsável pela sociedade na qual se encontra. A escola é campo fértil para o exercício da cidadania, uma vez que a escola configura-se como uma "micro-sociedade" (TEIXEIRA, 1956, p. 6).

O pensamento rousseauniano acentua a ideia de que a formação do homem e do cidadão ocorre simultaneamente. Quando há o desejo de educar o homem, seja para ele mesmo e para os outros, educa-se para a vida em sociedade, para a cidadania. Neste sentido, é evidente, também, para Rousseau, que a educação deve formar o cidadão:

A pátria não pode subsistir sem a liberdade, nem a liberdade sem a virtude, nem a virtude sem os cidadãos; tereis tudo se formardes cidadãos; sem isso só tereis maus escravos, começando pelos chefes do Estado. Ora, formar cidadãos não é tarefa para um dia; e para contar com eles quando homens é preciso instruí-los ainda crianças. (ROUSSEAU, 1964, p. 254).

A necessidade de educar para a cidadania está regulamentada na Lei de Diretrizes e Bases da Educação Nacional, Lei no 9.394/96, art. 32, em que salienta que, para o ensino fundamental, a formação básica do cidadão tem como objetivos:

II - a compreensão do ambiente natural e social, do sistema político, da tecnologia, das artes e dos valores em que se fundamenta a sociedade;

III - o desenvolvimento da capacidade de aprendizagem, tendo em vista a aquisição de conhecimentos e habilidades e a formação de atitudes e valores;

IV - o fortalecimento dos vínculos de família, dos laços de solidariedade humana e de tolerância recíproca em que se assenta a vida social. (BRASIL, 1996, p. 11).

Em consonância com a Carta Magna de 1988, a LDB no 9.394/96, que estabelece as diretrizes e bases da educação nacional, entende que a educação deve vincular-se ao mundo do trabalho e à prática social, tendo por finalidade o pleno desenvolvimento do educando, seu preparo para o exercício da cidadania e sua qualificação para o trabalho.

A escola deve formar valores e princípios democráticos para, então, ser efetivado um Estado democrático de direito, onde a opinião do cidadão seja ouvida em todas as instâncias de poder. A educação escolar voltada para a cidadania poderá desenvolver a liberdade de escolha do aluno e o seu poder de decisão, além disso, possibilitará a conscientização da existência dos direitos e deveres. E é somente a partir dessa educação que será efetivada a democracia no nosso país.

Anísio Teixeira parte do princípio que cidadania é participação do indivíduo (cidadão) nas instâncias da sociedade, tendo respeitados direitos e cumprindo seus deveres e, para se chegar a isso, a educação é o caminho. A educação idealizada por ele tem a função de formar/transformar indivíduos em cidadãos, aptos a viver em seu grupo social. Por sua vez, sendo a escola uma microsociedade, é o melhor lugar para se estimular e desenvolver o exercício da cidadania.

\section{Educação para a democracia}

Na virada do século XIX para o século XX, a educação da elite brasileira caracterizase por um ensino de caráter particular, acadêmico e intelectualista, tendo como referência a educação da escola francesa. Para o povo, havia lugares nas escolas primárias públicas, onde poucos poderiam se dirigir às escolas normais e técnico-profissionais.

O ensino brasileiro existente nesse período não atingia profundamente nenhuma grande camada popular e se caracterizava como uma educação de elite, de caráter excludente; a educação atingia os filhos de pais em boas 
condições financeiras (LIMA, 2011). Mas afinal, somos todos iguais? Candau (2003) tenta responder a essa pergunta:

\begin{abstract}
A afirmação da democracia é incompatível com um tecido sociocultural impregnado de preconceitos, discriminações e intolerâncias, componentes configuradores de relações sociais assimétricas e desiguais, presentes, em geral, de forma difusa, mas na verdade fortemente internalizadas e sustentadas com naturalidade nas sociedades latinoamericanas. (CANDAU, 2003, p. 9).
\end{abstract}

A trajetória de Anísio Teixeira traz a marca e o compromisso de oferecer a todos, indistintamente, uma escola democrática e de qualidade; a escola pública como ação estabilizadora dos novos processos sociais, econômicos e políticos que emergiram nas primeiras décadas do século XX. Para a entrada do país na sociedade industrial e moderna, era preciso, antes, dotar os indivíduos de conhecimentos básicos para bem desfrutar a vida individual e social. Educar para a democracia e a educação como direito de todos foram temas recorrentes em suas obras.

Anísio era um homem que lutava pela intervenção do Estado na educação, pelo fortalecimento da escola pública estatal. Assim, em uma sociedade tradicionalmente marcada de profundo espírito de classe e de privilégio, entendia que somente a escola pública seria verdadeiramente democrática e somente ela poderia ter um programa de formação comum, sem os preconceitos contra certas formas de trabalho essenciais à democracia (TEIXEIRA, 1971).

Nessa perspectiva, Anísio Teixeira teve importanteinfluência na elaboraçãodoManifesto dos Pioneiros da Educação Nova, em 1932. Este movimento, composto por educadores, surgiu diante dos graves problemas com a educação no Brasil. Segundo Ávila (2007), os estudiosos reivindicavam a educação para ricos e pobres indistintamente, pois a escola não poderia ter propósitos classistas. O educador ainda conclui dizendo que essa escola deveria ser a base para uma sociedade sem classes, democrática, em que a educação acontece conforme as suas aptidões (ÁVILA, 2007). Todavia, a existência de classes sociais nunca deixou de existir.

O referido Manifesto, assinado por 26 defensores do seu conteúdo, teve Anísio Teixeira como um de seus signatários. O documento visava à renovação do modelo de educação e, consequentemente, de escola. Os escolanovistas procuravam, por meio do Manifesto, uma educação obrigatória, proporcionada gratuitamente pelo poder público e que fosse leiga, ou seja, não estivesse sob a influência de ordem religiosa. Essa Nova Escola deveria ser implantada em todo o território nacional, extinguindo todas as desigualdades no oferecimento do ensino e a discriminação da classe pobre.

O Movimento da Escola Nova projeta a educação como um direito social e como instrumento de democratização de um ensino de qualidade, com a pesquisa qualificada e comprometida com os problemas sociais, na busca pela reinvenção da ciência, da cultura e da política, da própria sociedade brasileira. O trabalho produtivo faz a síntese entre antigas e novas representações, a fim de criar uma unidade superior (ÁVILA, 2007).

Logo, a educação progressiva, como Anísio Teixeira costumava falar, possuía uma ideologia democrática, de cunho liberal, na qual o sujeito possuía autonomia e liberdade de escolhas. Percebemos, então, que essa ideologia buscou tornar a escola mais adequada à sociedade contemporânea. Segundo o pensamento de Anísio, a escola deve representar uma comunidade, que forme cidadãos e se comprometa com uma melhor conexão com a vida social. Firma-se como situação concreta de vivência da vida em uma sociedade com perspectivas democráticas. 
não chegamos a ser democráticos senão por mimetismo e reflexos culturais de segunda mão. Na realidade, éramos autoritários, senão anacronicamente feudais. A estrutura de nossa sociedade não era igualitária e individualista, mas escravista e dual, fundada, mesmo com relação à parte livre da sociedade, na teoria de senhores e dependentes. (TEIXEIRA, 1971, p. 62).

Fundamentado em uma teoria sobre o Estado, Anísio defendia que a educação é um bem público e deveria ser concedida pelos governos, constituindo-se como um direito universal e não um privilégio de poucos. A educação não deve ser concebida como um processo deliberativo, sistemático, progressivo e inacabado de formação do indivíduo. Assim, para que a democracia aconteça, torna-se necessária a educação para a democracia, o que evidencia uma relação de dependência entre educação e Estado. No livro Educação não é privilégio (1971), o educador revela relatos de Gabriel Prestes ${ }^{4}$ sobre a convicção democrática da escola:

A instrução do povo é, portanto, sua maior necessidade. Para o governo, educar o povo é um dever e um interesse: dever, porque a gerência dos dinheiros públicos acarreta a obrigação de fornecer escolas; interesse, porque só é independente quem tem o espírito culto, e a educação cria, avigora e mantém a posse da liberdade. (TEIXEIRA, 1971, p. 58).

A escola assume a responsabilidade pela existência da democracia, tornando-se democrática através da expansão e renovação desse modelo experimental. Assim, a escola surgiria como ancoradouro para várias soluções apresentadas aos problemas democráticos, da civilização e da cultura de seu povo. A escola pública seria o meio e a democracia o fim:

Só existirá uma democracia, no Brasil no dia em que se montar no país a máquina que prepara as democracias. Essa máquina é a da escola pública. Mas não a escola sem prédios, sem asseio, sem higiene e sem mestres devidamente preparados e, por conseguinte, sem eficiência e sem resultados. Não a escola pública mais ou menos abandonada, sem prestígio social, ferida em suas forças vivas de atuação moral e intelectual e existindo graças à penosa e quase única abnegação de seus modestos servidores. E sim a escola pública rica e eficiente, destinada a preparar o brasileiro para vencer e servir com eficiência dentro do país. Essa nova escola pública menina dos olhos de todas as verdadeiras democracias - não poderá existir, no Brasil, se não mudarmos a nossa orientação a respeito dos orçamentos do ensino público. (TEIXEIRA, 1997, p. 230).

A educação escolar gera situações que formam pontos de contato entre diferentes grupos e contextos valorativos, que contribuem para a ampliação da mobilidade social e da democracia (LIMA, 2011). Para Dewey (1959, p. 93), "uma democracia é mais do que uma forma de governo; é, principalmente, uma forma de vida associada, de experiência conjunta e mutuamente comunicada".

Aideologia de Anísio encontra-se na defesa por uma democracia como motor educacional. Ele se preocupava em criar condições que viabilizassem as ações do homem. Segundo Lima (2011), Anísio tem clareza de que, ao defender a democracia, insere esta possibilidade numa construção que integra o quadro de mudanças que a civilização está vivendo, ou seja, participa

4. De Gabriel Prestes destaque-se: assumiu em 1893 a direção da Escola Normal de São Paulo, abrindo mão do cargo de deputado para o qual havia sido eleito com expressiva votação e em cujo exercício vinha se projetando; Prestes estudara na escola normal nos anos oitenta, nela se destacando como líder estudantil. Para Casemiro dos Reis Filho, os educadores que estiveram à frente da reforma educacional empreendida pelo poder público paulista foram Caetano de Campos, Gabriel Prestes e Cesário Mota Junior, entre outros. Estes consideravam que a educação consistia no mais eficiente instrumento para a construção de um Estado republicano democrático. (REIS FILHO, 1981) 
do dinamismo do culto ao que é novo. Por fim, educar para a democracia requer que a instituição se constitua como uma sociedade, na qual os alunos são os membros desse lugar e devem cooperar para a vida em conjunto. A Escola Nova surge como uma reprodução da sociedade, necessária para a formação de cidadãos.

\section{Considerações finais}

Em suas obras, Anísio Teixeira deixa claro que seu pensamento não tem pretensões de originalidade e apresenta como uma das principais influências o pensamento do filósofo americano John Dewey. Defensor de uma escola pública, universal e gratuita, em seu discurso, Anísio destaca a importância da educação escolar para a democracia. A visão e atuação desse educador, cuja percepção a respeito do papel da escola e de sua qualidade, marcou a história da educação brasileira. A ideia de educação de Anísio está intimamente relacionada com liberdade, democracia e cidadania. Porém, para que realmente ocorra a educação para a democracia, é necessário que a escola seja democrática. Para isso, os profissionais envolvidos com a educação devem desmistificar o caráter autoritário ainda presente em muitas instituições de ensino e promover a integração e a participação de toda a comunidade escolar. Somente assim, nessa "micro-sociedade", designada por Anísio para definir o espaço escolar democrático, o aluno estará preparado para a vida cotidiana.

A contribuição fundamental de Anísio Teixeira para a filosofia da educação está na defesa da dinâmica da democracia como motor educacional. O modelo de educação anisiano apoia a consciência de estar vivendo em um mundo em vital transformação e que a democracia é um processo em igual modificação, a ser consolidada como modo de vida.

\section{Referências}

ÁVILA, V. P. S. Democracia e justiça social: a defesa de Anísio Teixeira registrada no livro Educação no Brasil. Roteiro, Joaçaba, v. 31, n. 1, p.61-74, 2007. Disponível em: < http://editora.unoesc.edu. br/index.php/roteiro/article/view/338 >. Acesso em: 15 dez. 2016.

CORDEIRO, C. M. F. Anísio Teixeira: uma "visão" do futuro. Estudos Avançados, São Paulo, v. 15, n. 42, p. 241-258, maio/ago. 2001. Disponível em: <http://www.scielo.br/scielo.php?script=sci arttext\&pid=S0103-40142001000200012 >. Acesso em: 10 dez. 2016. doi: http://dx.doi. org/10.1590/S0103-40142001000200012.

CANDAU, V. Somos todos iguais? Escola, discriminação e educação em direitos humanos. Rio de Janeiro: DP\&A, 2003. 136 p.

DEWEY, J. Como pensamos. São Paulo: Companhia Editora Nacional, 1959. 292 p.

FARIAS, D. R.; AMARAL, L. M. S; SOARES, R. C. Bibliografia de Anísio Teixeira. Revista Brasileira de Estudos Pedagógicos, Brasília, v. 82, p. 207-242, 2001. Disponível em: <http://rbep.inep.gov.br/ index.php/rbep/article/view/926> . Acesso em 10 jan. 2017. doi: http://dx.doi.org/10.24109/21766681.rbep.82i200-01-02.926.

LIMA, J. F. L. Educar para a democracia como fundamento da educação no Brasil do século 
XX: a contribuição de Anísio Teixeira. Educar em Revista, Curitiba, n. 39, p.225-239, 2011. Disponível em: <http://www.scielo.br/scielo.php?pid=S0104-40602011000100015\&script=sci abstract\&tlng=pt $>$. Acesso em: 10 jan. 2016. doi: http://dx.doi.org/10.1590/S010440602011000100015.

NUNES, C. Anísio Teixeira. Recife: Massangana, 2010. 152 p.

- Anísio Teixeira entre nós: a defesa da educação como direito de todos. Educação \& Sociedade, Campinas, v. 73, p. 9-40, dez. 2000. Disponível em: < http://www.scielo.br/scielo. php?pid=S0101-73302000000400002\&script=sci_abstract\&tlng=pt $>$. Acesso em: 15 jan. 2016. doi: http://dx.doi.org/10.1590/S0101-73302000000400002.

REIS FILHO, C. A educação e a ilusão liberal. São Paulo: Cortez e Autores Associados, 1981. 214 p.

ROUSSEAU, J. J. Discours sur l'économie politique. In: . Oeuvres complètes. 3. ed. Paris: Bibliothèque de La Pléiade, 1964.

SAVIANI, D. História das ideias pedagógicas no Brasil. Campinas: Autores Associados, 2007. 473 p. TEIXEIRA, A. Educação para a democracia: introdução à administração educacional. 2. ed. Rio de Janeiro: Editora UFRJ, 1997. 263 p.

. Educação não é privilégio. Rio de Janeiro: Editora UFRJ, 1971. 250 p.

. O processo democrático de educação. Revista Brasileira de Estudos Pedagógicos, Rio de Janeiro, v. 25, n. 62, p.3-16, 1956.

. Por que "Escola Nova"? Boletim da Associação Bahiana de Educação. Salvador, n.1, p. 2-30, 1930. Disponível em: <http://www.bvanisioteixeira.ufba.br/artigos/nova.htm>. Acesso em: 13 jan. 2016.

Submetido em 12 de janeiro de 2017

Aprovado em 13 de maio de 2017 